\title{
Causative Factors of Unsuccessful Dacryocystorhinostomy and the Surgical Technique of Revision External Dacryocystorhinostomy
}

\author{
Ved Prakash Gupta ${ }^{a}$ Pragati Guptab Rigved Gupta ${ }^{a}$ \\ a University College of Medical Sciences and G.T.B. Hospital and ${ }^{b}$ Lady Hardinge Medical College, New Delhi, India
}

We highly appreciate the article by Konuk et al. [1]. We would like to share additional findings observed in unsuccessful endonasal or external dacryocystorhinostomy (DCRs). Absent bony ostium, intact lacrimal fossa with anterior lacrimal crest and nonperforation of the sac have been encountered frequently in our practice. The osteotomy anterior to anterior lacrimal crest with intact lacrimal fossa bones was noted in 4 cases despite 1-4 previous DCRs. The bone opposite the common canaliculus had not been removed in the majority of cases. Anastomosis of lacrimal fascia flaps with nasal mucosal flaps, diverticula, fibrous membrane occluding common internal punctum and postoperative lacrimal fistula which turned out to be tubercular were other causes of failure of DCR.

Surgery for unsuccessful DCR remains difficult, time consuming and challenging. The anesthetic infiltration at the medial canthus as mentioned by the authors [1] may not sustain the prolonged revision DCR surgery. We prefer infraorbital, infratrochlear and anterior ethmoidal nerve blocks, infiltration at incision site and nasal packing [2]. The authors disinserted the anterior limb of the medial canthal tendon, which may result in iatrogenic telecanthus. Exposure of the upper part of the lacrimal sac may be achieved by cut- ting the inferior portion or dividing the medial canthal tendon $[3,4]$. However, the cut ends must be sutured while closing the wound [4]. Even a disinserted canthal tendon needs to be sutured to the periosteum over the nasal process of maxilla. The authors irrigated methylene blue in the lacrimal sac for identification. This does not facilitate the sac incision site over the internal common canalicular ostium and offers no advantage over visualization of the Bowman probe to ensure full-thickness incision [2]. Moreover, methylene blue spills in the surgical field following incision into the sac and interferes with subsequent tissue identification [2].

We would like to highlight the few additional operative steps routinely performed by us in revision DCRs. All the measures to prevent intraoperative bleeding are adopted. To prevent damage to the nasal mucosa, the nasal pack is removed before osteotomy and reinserted after osteotomy [2]. The ideal osteotomy includes removal of all bone between the medial wall of the sac and the nose, 3-4 $\mathrm{mm}$ of anterior lacrimal crest, deroofing of the upper part of the nasolacrimal canal and removal of the $5-\mathrm{mm}$ bone opposite the common canaliculus opening [4]. Longitudinal incision in the sac must involve the lowest part of the sac to avoid sump syndrome. Internal punctoplasty is required for membrane occluding internal ostium. If nasal mucosa is not available, the sac flap may be sutured to the periosteum overlying the anterior lacrimal crest [5]. Buccal mucous membrane grafting may improve the success of DCR in cases complicated by scarring or mucosal shortage [6].

\section{References}

- 1 Konuk O, Kurtulmusoglu M, Knatova Z, Unal M: Unsuccessful lacrimal surgery: causative factors and results of surgical management in a tertiary referral center. Ophthalmologica 2010;224:361-366.

2 Patrinely JR, Gigantelli JW: Dacryocystorhinostomy; in Linberg JV (ed): Lacrimal Surgery. Edinburgh, Churchill Livingstone, 1988, pp 151-167.

3 McCormick SA, Linberg JV: Pathology of nasolacrimal duct obstruction: external DCR; in Linberg JV (ed): Lacrimal Surgery. Edinburgh, Churchill Livingstone, 1988, p 171.

4 Welham RA, Wulc AE: Management of unsuccessful lacrimal surgery. Br J Ophthalmol 1987;71:152-157.

5 Holt GR, Holt JE, Cortez EA: Dacryocystorhinostomy utilizing an anterior lacrimal sac flap to periosteum technique. Otolaryngol Head Neck Surg 1979;87:174-182.

-6 Tao JP, Luppens D, McCord CD: Buccal mucous membrane graft-assisted lacrimal drainage surgery. Ophthalmol Plast Reconstr Surg 2010;26:39-41.

\section{KARGER}

Fax +41613061234 E-Mail karger@karger.ch www.karger.com
Dr. Ved Prakash Gupta

Oculoplasty, Orbital and Lacrimal Services, Department of Ophthalmology

University College of Medical Sciences and G.T.B. Hospital

Delhi 110095 (India)

E-Mailvpg275gv@yahoo.co.in 